\title{
Performance measurement and management: A system of systems perspective
}

\author{
Mike Bourne* \\ School of Management, Cranfield University, Cranfield, Bedfordshire MK430AL, UK \\ T: +44 (0)1234 754514; E: m.bourne@cranfield.ac.uk \\ Monica Franco-Santos \\ School of Management, Cranfield University, Cranfield, Bedfordshire MK430AL, UK \\ T: +44 (0)1234 751122; E: monica.franco@cranfield.ac.uk \\ Pietro Micheli \\ Warwick Business School, University of Warwick, Coventry, CV4 7AL, UK \\ T: +44 (0)24 7615 0882; E: pietro.micheli@wbs.ac.uk \\ Andrey Pavlov \\ School of Management, Cranfield University, Cranfield, Bedfordshire MK430AL, UK \\ T: +44 (0)1234 751122; E: andrey.pavlov@cranfield.ac.uk
}

* Corresponding author 


\title{
Performance measurement and management: A system of systems perspective
}

\begin{abstract}
Despite changes in tools and practices, the conceptual foundations of performance measurement and management (PMM) are still predominantly rooted in control systems research. While PMM approaches have delivered significant organizational benefits, including creating alignment, supporting monitoring and control, and enabling prediction and optimization of resource allocation, this paper argues that this paradigm is not capable of responding to increasingly complex and highly uncertain organizational environments. Drawing on ideas emerging in the literature on systems engineering and complex systems, we propose a novel perspective that considers PMM from a 'system of systems' (SoS) point of view, whose essential characteristics are autonomy, belonging, connectivity, diversity, and emergence. After identifying the assumptions underpinning existing PMM approaches, we outline a SoS-based paradigm to PMM and conclude by articulating the main implications for the practice of PMM and setting out a research agenda.
\end{abstract}

Keywords: Performance management, performance measurement, control systems, system of systems. 


\section{Introduction}

Since the rise of modern corporations, performance measurement and management (PMM) has been used to help organizations achieve their goals and deliver their mission. PMM systems have been introduced to facilitate the implementation of business strategies (Bititci et al. 2015), to provide alignment within and between organizations (Danese and Romano 2012; Liang 2015; Maestrini et al. 2017), to optimize resource allocation and support decision-making (Berrah, Mauris, and Vernadat 2004), and to improve performance (Franco-Santos, Lucianetti, and Bourne 2012; Neely 2005). However, despite considerable progress, managing performance effectively continues to be a major organizational challenge (Cappelli and Tavis 2016; Micheli and Mura 2017).

While PMM theory and practice have developed and evolved significantly over the years, various authors have started to question whether the dominant PMM paradigm, rooted in the control systems literature, is suitable in increasingly volatile and uncertain contexts. PMM is currently regarded as a collection of management processes supported and enacted through the use of tools and techniques such as scorecards, measures, targets, performance reviews and incentives that are developed centrally and cascaded throughout the organization (Franco-Santos et al. 2007; Malmi and Brown 2008). This approach to PMM reflects the view of organizations as 'monolithic' systems, which consist of different parts that are interconnected to achieve a particular purpose not attainable by each part on its own (Rechtin 1991). This perspective is appropriate when problems can be clearly defined, phenomena can be reduced using parsimonious models and theories, and the prediction of optimal outcomes is the main goal (Maier 1998).

Current evidence, however, shows that the reality of most organizations is rather different and PMM scholars have highlighted the potential inadequacy of existing approaches. For example, Melnyk et al. (2014) identified instances of misalignment between organizational strategy and PMM systems, and suggested that the relationship between the two should be reframed. Similarly, Bititci et al. (2012) raised 
several questions about PMM's readiness for an emerging context characterized by disruptive and transformational change. However, despite calls to review and rethink PMM, little has been done to offer viable paradigms that either complement or replace the existing one.

This paper suggests that novel and practically relevant PMM research can be developed by employing a 'system of systems' (SoS) perspective (Ackoff 1971), which has been debated in recent systems engineering and complex systems literature (Sauser, Boardman, and Verma 2010). A SoS has been defined as "a metasystem, comprised of multiple embedded and interrelated autonomous complex subsystems that can be diverse in technology, context, operation, geography, and conceptual frame. These complex subsystems must function as an integrated metasystem to produce desirable results in performance to achieve a higher-level mission subject to constraints" (Keating, Padilla, and Adams 2008, 24). The adoption of a SoS approach in PMM could offer a suitable alternative to the challenges posed by the dominant paradigm, particularly in complex and uncertain environments. For example, a SoS approach explicitly favours learning and adaptation, rather than control and alignment, which are critical capabilities for operating in high uncertainty contexts (Otley and Soin 2015). Similarly, its main aim is neither prediction nor optimization (Otley and Berry 1980; Malmi and Brown 2008), but rather 'navigation' (i.e., to enhance understanding and learning about the problem at hand, so that progress towards the intended goals is achieved) (DeLaurentis and Callaway 2004).

To discuss the distinctiveness and proposed advantages of a SoS perspective in PMM, this paper starts by reviewing the current dominant paradigm in PMM, founded in the control systems literature. Subsequently, the literature on systems of systems is examined and an alternative conceptualization of PMM is proposed. The paper concludes by providing several examples of using PMM according to the SoS paradigm, articulating a research agenda to guide the development of further studies in this area, and identifying salient practical implications. 


\section{Performance measurement and management: The dominant}

\section{paradigm}

Conceptualizations of PMM have developed over the years across different organizational forms (FrancoSantos et al. 2007). In the early 1900s, performance measures were introduced as control mechanisms, which could support budgeting and planning processes in large corporations such as du Pont and General Motors (Chandler 1977). According to Johnson (1981), these performance measures played a fundamental role in supporting the development of these new organizational processes. In the late 1980 s and early 1990s, dissatisfaction with purely accounting-based measures (Johnson and Kaplan 1987) led to the development of a series of multi-dimensional PMM frameworks (Keegan, Eiler, and Jones 1989; Cross and Lynch 1989; Fitzgerald et al. 1991). One of the most widely used PMM framework has been the Balanced Scorecard (Kaplan and Norton 1996) due to its capacity to connect strategic objectives with performance measures and action plans (Bourne et al. 2000; Bourne et al. 2002) and to link financial and non-financial indicators (Ittner, Larcker, and Randall 2003).

These developments in PMM have led to what can be described as the current dominant approach, which is mainly based on a control systems perspective. Indeed, many authors have claimed that PMM systems are important means for monitoring and controlling resources (Franco-Santos, Lucianetti, and Bourne 2012) and are "ultimately responsible for maintaining alignment and coordination" (Melnyk et al.

2014, 213) (see also Ittner and Larcker 2003; Hanson, Melnyk, and Calantone 2011). For example, Dossi and Patelli's (2010) study of multinational firms found that PMM systems enabled corporate control of subsidiaries. The importance attributed to PMM in creating strategic alignment has led to a number of studies focused on the design of performance measures and targets which are consistent with strategic objectives (Kaplan and Norton 2008; Hoque 2014; Micheli and Mura 2017). 
Another fundamental tenet in the current PMM paradigm is that the design of PMM tools should progressively cascade from the corporate level to business units, teams and individuals (Micheli and Neely 2010). In so doing, PMM is not just a way to ensure alignment, but also to create centralization of decisions over resource allocation and a mechanism for top management to exert influence (Kaplan and Norton 2008). Consequently, performance reviews should be undertaken in a consistent fashion and pace, so as to feed information back to the corporate centre (Bourne et al. 2000; Martinez, Pavlov, and Bourne 2010).

The cascading and review processes therefore attempt to ensure that units, teams and individuals respond and contribute to the same corporate objectives and that a sufficient level of accountability is attained (Kolehmainen 2010). To do so, the same performance measures and targets are often designed and implemented across the organization, and the performance of different units and individuals is often assessed separately and then compared (Cappelli and Tavis 2016). Such a configuration requires that a 'golden thread' is established across organizational levels and this leads to a tight coupling between units.

In both academic studies and practical implementations, PMM systems have been associated with the optimization of an organization's resource allocation and value chain (Srimai, Wright, and Radford 2013; Yang and Modell 2015). This has been partly attributed to PMM's task to ascertain the 'truth' about organizational resources and processes (Micheli and Mari 2014), and partly to its capacity, through tools such as strategy maps and success maps (Kaplan and Norton 2000; Neely, Adams, and Kennerly 2002), "to be predictive, as [they] aspire to show how decisions made in the present could impact future results" (Buytendijk, Hatch, and Micheli 2010, 338). In sum, by creating alignment, ensuring that resources are managed appropriately, and enacting feedback loops across the organization, PMM has often been regarded as an important means to improve performance (Neely 2005; Koufteros, Verghese, and Lucianetti 2014). 


\section{Limitations of the dominant paradigm}

While PMM systems have been showed to play a mainly positive role in organizations (Franco-Santos, Lucianetti, and Bourne 2012), concerns are being raised regarding the appropriateness of the current paradigm for increasingly complex, volatile and uncertain environments. For example, Melnyk et al. (2014) have challenged PMM's capacity to provide direction when the environment is so turbulent that it would take too long to preserve consistency between strategy and PMM. Similarly, in complex settings such as public administration, where central and local policies and goals often differ, "it is questionable whether the establishment of a pervasive 'golden thread' would be either feasible or desirable" (Micheli and Neely 2010, 598). Some scholars have also shown that PMM - understood as a monitoring and control device can be detrimental for highly dynamic and fast-moving organizations as it can stifle learning and critical thinking which are of paramount importance for their survival (Neely and Al Najjar 2006). Furthermore, the idea of PMM as a predictive means that can help organizations anticipate outcomes and prepare for them is often questioned in environments which are constantly changing (Otley and Soin 2015). Due to these limitations, it can be argued that a new way of seeing and understanding PMM that can be applied to complex and highly uncertain environments is required.

In recent years, systems engineering and complex systems scholars have also been debating novel approaches to dealing with complexity and uncertainty (Gorod et al. 2015). One of the most promising proposals has been to focus on what is conceptualised as a 'system of systems' perspective (DeLaurentis and Callaway 2004; Keating et al. 2003; Keating, Padilla, and Adams 2008; Boardman and Sauser 2006; Sauser, Boardman, and Verma 2010). This perspective is based on the idea that complex and uncertain issues cannot be addressed following a unitary, "monolithic" system approach (i.e., a way of thinking that assumes that a central system can be designed to 'solve' the problem). Instead, this perspective implies that these issues require a more holistic approach and assumes that a set of independent systems can be 
bundled together to produce a multitude of responses that can help decision makers navigate through the complexity and make progress (Boardman and Sauser 2006; Sauser, Boardman, and Verma 2010). The types of issues the SoS perspective is aiming to address resonate with the ones faced by the dominant PMM paradigm. Because of this similarity, the SoS concept is now explored in greater detail and it is then applied to PMM with the aim of developing an alternative paradigm.

\section{An overview of system of systems research}

The concept of SoS emerged in response to the challenges posed by the complexity, ambiguity, and scale of modern problems (Sauser, Boardman, and Verma 2010). In line with previous research, SoS scholars define a system as "a collection of parts and their relationships assembled together to form a whole with new properties, behaviours, and purposes" (Sauser, Boardman, and Verma 2010, 803). In certain cases, however, the constituent parts of the system are complex dynamic systems in their own right, making up an overarching structure whose properties are significantly different from those of single systems. This structure - a system of systems - has been defined as "an arrangement of independent and interdependent systems that collectively exhibits unique capabilities" (Baldwin, Boardman, and Sauser $2013,65)$. The multiple systems within a SoS are "disparate, diverse, autonomous and asynchronized entities [that] work together without losing their individual sense of purpose and without loss of idiosyncratic capability, in order to realize some higher-level and otherwise unattainable purpose" (Sauser, Boardman, and Verma 2010, 805).

For example, NATO uses a SoS approach to describe the way it currently views and operates in the 'theatre of war' (Mahmood 2016). Historically, engaging in a war was considered as a mechanistic and monolithic task. Countries understood their defence system as unitary and their enemy as 'a constant', whose power could be diminished through the use of information, technology and an appropriate strategy 
(Mahmood 2016). However, many modern wars - from the ones in Vietnam and Afghanistan to the current 'war on terror' - cannot be framed according to this linear and closed system approach. These are highly complex and emergent conflicts where the enemy is continuously changing and adapting, and wars are no longer 'won' or 'lost'. The potential for conflict is constant; addressing it demands more than just information, technology and an appropriate strategy. It requires multiple independent, but connected systems that go beyond the Army, the Air Force and the Navy to include Governments, NGOs and civilians. Other examples of SoSs discussed in the literature stretch from other military and intelligence systems (Svendsen 2015) to the Yellow Cab system in New York City (Gorod et al. 2008) and air transportation systems (DeLaurentis and Ayyalasomayajula 2009).

In the corporate sector, supply chains are used as examples of SoSs (Tsan-Ming 2016), as they consist of a number of autonomous and interdependent complex systems - in this case companies and business units (Chan 2011). The success of a supply chain does not result from the aggregation of the individual operations and performance of each company. Success depends on the integrated and adaptive activities as well as the relationships among the companies. In the past, supply chain problems have commonly been addressed through a centralized approach focused on information sharing and contractual and measurable responsibilities (Chanand and Chan 2009; Akyuz et al. 2010). However, more recent work has questioned this approach in favour of a more open and holistic one that draws on the principles of SoS research (Chan 2011; Tsan-Ming 2016).

\subsection{Main characteristics of system of systems}

Although the term itself has a long history (Ackoff 1971), research in SoS gained momentum in the late 1980s, driven by the application of SoS thinking in the U.S. military (Sauser and Boardman 2008). The systems engineering and complex systems literature acknowledges the existence of different types of systems (e.g., monolithic, complex adaptive, and SoS) and highlights that each of these types has 
distinguishing characteristics or 'traits' (Mostafavi et al. 2011; Zhu and Mostafavi 2014). Although what constitutes a SoS may differ depending on context, Boardman and Saucer (2006) provide a succinct set of characteristics that can help understand what a SoS is and what it is not. These have become widely adopted in the literature (Baldwin, Boardman, and Sauser 2013; DeLaurentis and Ayyalasomayajula 2009; Gorod et al. 2008; Sauser, Boardman, and Verma 2010) and include autonomy, belonging, connectivity, diversity, and emergence:

- Autonomy refers to the ability of constituent parts or sub-systems within a SoS to set and pursue its own goals, not requiring external control (Baldwin, Boardman, and Sauser 2013) and being managerially and operationally independent (Gorod et al. 2008). This is necessary because the ability of the overall SoS to attain its purpose depends on the constituent parts maintaining their full functionality and the freedom to learn and adapt (Sauser, Boardman, and Verma 2010).

- The constituent parts of a SoS are fully functional systems in their own right, which means that they can join different SoSs or indeed operate on their own. The relationship between the constituent parts and the SoS as a whole is thus one of belonging, where individual systems choose freely to associate themselves with a large SoS (Sauser, Boardman, and Verma 2010). This choice reflects the needs and purposes of both the individual system and the overall SoS (Baldwin, Boardman, and Sauser 2013; Gorod et al. 2008).

- Connectivity refers to the kind of relationships that exists between the constituent parts of the SoS. As a SoS is a loose structure that evolves as individual autonomous systems choose to belong to it or to leave it, the relationships between these systems cannot be designed in advance (Sauser, Boardman, and Verma 2010). Rather, these relationships are dynamically formed (Baldwin, Boardman, and Sauser 2013) and the connections between the parts of a SoS can be described as network-centric (Gorod et al. 2008) and loosely coupled (Weick 1976; Lo et al. 2014; Glassman 1973). 
- Diversity refers to the heterogeneity of constituent parts within a SoS (Gorod et al. 2008) and is a necessary condition for making the overall SoS resilient. Sauser et al. $(2010,807-8)$ note that "diversity through a variety of viewpoints, processes, technologies, and functionalities ensures richness, and the SoS must be able to leverage this in an unencumbered fashion".

- Finally, as any complex dynamic system, a SoS is characterized by emergence, which means that the SoS produces properties and functions that cannot be traced back causally to its constituent parts (Baldwin, Boardman, and Sauser 2013). Such properties and functions are qualitatively novel, and their characteristics cannot be explained solely by the nature of the parts that generated them (Bunge 2014).

The above characteristics make SoS capable of addressing problems that are outside the scope of more traditional monolithic systems. Furthermore, SoS are assumed to deal with more effectively with 'wicked' rather than 'tame' problems (Rittel and Webber 1973) that require a multiple and integrated complex response (Keating, Padilla, and Adams 2008). They take into consideration the technical and the social aspects of the phenomena they deal with, and their purpose is to help decision makers navigate under uncertainty and respond to the needs of multiple stakeholders (DeLaurentis and Ayyalasomayajula 2009; DeLaurentis and Callaway 2004). In other words, SoS thinking enables decision-makers to act when the goal "is not prediction (which remains notoriously difficult to do over the long run), but instead is an understanding that the essence of the problem - the hard-to-grasp insight-likely appears only at this elevated perspective" (DeLaurentis and Callaway 2004, 803). It is because of this capability that SoS has been used in many research studies that examine ambiguity, complexity, and change (Gorod et al. 2008). 


\section{Performance measurement and management: A system of systems}

\section{paradigm}

Applying the five characteristics of the SoS perspective (Sauser, Boardman, and Verma 2010) to PMM helps both to evaluate the limitations of the dominant paradigm and to develop an alternative new paradigm for PMM. These characteristics and their implications are summarised in Table 1 and explained in detail in sections below.

Table 1. The dominant and the SoS paradigms in PMM.

\begin{tabular}{lcc}
\hline Attributes & Dominant paradigm & System of systems paradigm \\
\hline Autonomy & Control and alignment & Learning and adaptation \\
Belonging & Centralization and cascading & Localization and orchestration \\
Connectivity & Tight coupling & Loose coupling \\
Diversity & Homogeneity & Heterogeneity \\
Emergence & Prediction and optimization & Navigation and improvement \\
\hline
\end{tabular}

\subsection{Autonomy}

In the dominant paradigm, PMM practices are characterized by alignment and control. Although such a view has traditionally provided a basis for efficient resource allocation, in environments that are characterized by rapid pace of change and high degree of uncertainty, this view could hinder adaptability which is necessary for maintaining competitive advantage (McGrath 2013). However, the focus on integration and alignment prevalent in the PMM literature (Melnyk, Stewart, and Swink 2004; Hoque 2014) suggests that the dominant PMM paradigm tends to view autonomy with caution.

In contrast, a SoS perspective would advocate allowing the constituent parts of the system to have independent purposes and functions. Such configuration would be based on greater devolvement and autonomy and would prioritize learning and adaptation over top-down alignment of objectives and behaviours. The corresponding PMM practices might include allowing different units to identify and 
manage their own stakeholders, develop their own performance appraisals and design appropriate indicators, and set their own compensation and reward policies. For example, in large conglomerates with various subsidiaries, each unit could develop local indicators and targets, and performance information may or may not be reported centrally. Within a supply chain, businesses could decide to develop joint objectives and related performance indicators, but different performance measurement frameworks could be utilized internally.

\subsection{Belonging}

In the dominant paradigm, the different components of the system are interrelated and the organizational structure is highly centralized. For example, key performance indicators and targets are often designed at the corporate level and then cascaded down to the business unit, team and individual levels. This integration enables centralized decision making and the cascading of those priorities to be established at the top, and assumes that there is an optimal way of assessing performance that is valid regardless of context. The dominant paradigm thus assumes that the sub-systems, whether subsidiaries or partners in a network, have limited choice regarding whether to belong to the overall system.

In a SoS, however, the different sub-systems are meant to address specific problems, so, in order to address a multifaceted organizational performance challenge, they may not necessarily need to be fully integrated. In a SoS, belonging to the system that facilitates the emergence of the 'whole' is a choice. Depending on the nature of the performance problem, decisions would need to be made about whether and to what extent different sub-systems join the larger system. The presence of choice in turn suggests that leaders may need to focus on orchestrating the functioning of the SoS through stimulating and coordinating the interactions between the sub-systems rather than attempting to impose a designed solution by means of central control and alignment. 
While this characteristic of SoS may have limited application within unitary organizations, it becomes increasingly relevant in settings that bring together independent units or firms, for example, partnerships, supply chains, or organizational ecologies. In these contexts, PMM practices may take the form of stakeholder consultations, organizing joint workshops, and collaborative development of PMM systems. Such work may be undertaken for specific activities or programmes, for example performance indicators could be developed jointly by different partners, but only in relation to a certain project.

\subsection{Connectivity}

The dominant view of PMM assumes that the connections between the different parts of the system must be designed simultaneously with the design of the parts themselves. This in turn implies that various subsystems should be tightly coupled at all hierarchical levels (Lo et al. 2014). For example, performance measures selected at the level of the SoS would need to be fully translatable into performance measures at the level of sub-systems, which would enable efficient cascading throughout levels of hierarchy.

A SoS perspective, instead, would advocate loosely coupled connections among sub-systems. As sub-systems within a SoS operate within their own environment which ensures their effectiveness, these sub-systems may need indicators and scorecards that could be misaligned with those of other sub-systems and with the overall SoS (Melnyk et al. 2014; Pongatichat and Johnston 2008). PMM practices may therefore need to focus on establishing a continuous dialogue about performance within the SoS and using performance information to support this dialogue, rather than require that performance measures and scorecards of all constituent sub-systems be tightly integrated and aligned. This approach would be particularly suitable in networks of organizations with distributed authority, such as airports where various partners contribute to a diverse set of operations, but pursue divergent objectives. Here, some common objectives and targets may be introduced, but the majority would be independent and different. 


\subsection{Diversity}

The dominant PMM paradigm favours homogeneity and consistency. From a PMM viewpoint, performance measures and targets are derived from strategic priorities, which are defined in advance in the strategic planning process (Melnyk, Stewart, and Swink 2004; Dror and Barad 2011). While this approach may work in stable and relatively closed contexts, it also implies that performance information is collected deductively, i.e., to provide evidence over aspects that are recognised to be important.

In a more dynamic and complex environment, relevant aspects of performance may not be known in advance, and therefore PMM systems should be able to capture a wider range of phenomena. For example, different sources of data could be utilized (e.g., customer, environmental, general trends) to uncover potential patterns rather than to prove hypotheses. Furthermore, a SoS perspective suggests the importance of managing and evaluating the performance of the whole system taking synergies into account (e.g., the organization or network of organizations), rather than focusing on separate units or individuals. Even in presence of common corporate objectives to be cascaded throughout an organization, heterogeneity should be ensured, as business units may contribute to the objectives differently. For example, the organization may have cost reduction as a key priority, but some units may contribute to that more effectively by increasing customer satisfaction, as it would eventually reduce cost by diminishing expenditure in advertising and business development. Similarly, performance indicators may need to be introduced specifically to look for information that is not immediately relevant but that may represent important weak signals in the environment (Gimbert, Bisbe, and Mendoza 2010), for example changing trends in customer preferences or adoption of new technology. 


\subsection{Emergence}

The dominant view of PMM has prediction and optimization as ultimate goals. These goals derive from a planning-based approach to managing performance and require a substantial degree of foresight on the part of the organization's leaders. Indeed, tools such as budgets, forecasts, strategy maps, and ERP systems are based on the belief that the determinants of success can be known in advance and that management systems can be optimized to deliver it. On the contrary, the SoS perspective emphasizes the fact that the system's functionality and performance are an outcome of a continuously evolving complex configuration of its constituent parts (Baldwin, Boardman, and Sauser 2013). Moreover, the precise contribution of these constituent parts cannot be known, which means that the performance of the system cannot be optimized through the use of control-based PMM practices. In fact, deploying such practices may produce the opposite results, which is widely documented in the literature on the unintended consequences of PMM (Kerr 1995; Dahler-Larsen 2014; Ridgway 1956).

Instead, a PMM view that is congruent with the SoS perspective would provide managers with the appropriate information at the appropriate times, enabling them to 'navigate' (DeLaurentis and Callaway 2004) their way through the multiplicity of options that they constantly face. The corresponding PMM practices may include encouraging and evaluating small-scale experimentation and rapid prototyping in order to observe the system's response; collecting a wide range of performance data and actively searching for weak signals in the environment; employing simulation modelling in order to evaluate probable scenarios; creating an architecture for performance information that connects key decision makers; and providing training that is focused on reducing bias and improving the quality of decision making. In other words, a PMM approach that reflects the emergent nature of a SoS would need to enable managers to navigate the current situation and make improvements in the present rather than to predict and optimize a future state. 


\subsection{PMM in practice}

This section presents two examples to highlight the differences between a traditional PMM approach and a SoS-based one.

A typical process for designing a PMM system in a large private firm begins with the elaboration of a strategy map - usually by the senior management team - that is linked to the organization's main priorities and that helps clarify and communicate strategy (Kaplan and Norton 2000). Subsequently, a corporate scorecard including a number of Key Performance Indicators (KPIs) and targets is created to support the implementation of the strategy and to help gather relevant information to understand whether strategic objectives are being achieved. Normally, KPIs included in the scorecard are cascaded throughout the organization so that the different departments and functions are aligned with the overarching strategy. These KPIs are then used in the organization to review and reward performance. From this point of view, PMM is perceived to be a single, unitary system, whose role is to perform a unique function not performable by the elements alone (Rechtin 1991). This approach requires base-level abstraction (e.g., only a few dimensions of performance are meant to capture the overall work of units, teams and individuals) and multi-level aggregation (i.e., the sum of the measured performance of all units, teams and individuals equals the whole organizational performance).

A SoS approach to PMM, however, would call for a different way of developing and using a PMM system. We illustrate this approach with a set of PMM practices in an organization that we have studied for over a decade (Neely, Micheli, and Martinez 2006; Bourne and Bourne 2011). This organization is one of the 'Big Six' energy suppliers in the UK and has developed a way of managing performance that parallels the SoS approach. While the starting point of developing a PMM system in this organization would still be a corporate level strategy map, the senior management team would engage a range of stakeholders in order to understand their different expectations and aims. This exercise led to the creation of a tentative strategy 
map; however, its deployment was different. Instead of identifying and cascading a set of KPIs following a linear and unitary system perspective, the organization focused on communicating and negotiating the objectives and relationships included in the map with managers in the regional businesses. The map thus captured the strategic intent without overly constraining the sub-systems tasked with satisfying the multiple and diverse stakeholders' expectations. In this way, the company's overarching objectives were agreed and detailed with the three regional businesses. Each regional business then created its own strategy map integrating the task of supporting the strategic intent of the company with that of serving the needs of the local stakeholders. Devolved decisions over how to design and implement business-level strategy maps thus reflected the autonomy of regional businesses. Many individual indicators were not routinely reported at corporate level, yet performance information could be collated across units for specific purposes (e.g., when comparing performance across common criteria or when implementing standardized processes), thus supporting the connectivity of the individual business units within the system. Diversity was fostered by allowing the introduction of different types of KPIs depending on the specific context the business units were operating in. Finally, despite differences across sites and operations, the organization reviewed and rewarded performance mainly on the basis of corporate level results, recognising that performance was an emergent property generated through the complex interaction of multiple elements within the system, rather than a simple aggregation of the performance of individuals, teams and business units.

Supply chains provide another context where the five main attributes of SoS could also transform the way in which PMM is understood and practiced. Firstly, organizations within a supply chain could develop a common set of KPIs, but they could also autonomously create their own indicators to capture their local contexts and drivers of performance more accurately. On the basis of specific contracts or projects, the firms could decide whether it would be appropriate and relevant for them to contribute and, 
therefore, belong to the overall supply chain and participate in the joint effort of managing performance. Depending on the changes in the business environments or within the organizations, connectivity between the various firms within a supply chain, and therefore between their PMM systems, could become looser or tighter. Heterogeneity and diversity in PMM would be very important aspects, as they would enable individual organizations within the supply chain to test practices locally and to gather data in various ways. For example, firms closest to the consumer may choose to concentrate on exploring hidden or potential customer needs as well as serving the espoused ones. Finally, the performance of the firms within the supply chain is an emergent property that is inseparable from the operation of the supply chain as a whole, which means that it has to be assessed and managed holistically, rather than by focusing on the detail of specific achievements or functional results.

\section{Discussion and Conclusions}

This paper has applied the SoS perspective to the dominant paradigm in PMM research and practice to outline an alternative approach, which regards complexity and uncertainty as normal features of organizational environments rather than exceptions to otherwise stable and predictable contexts. Although this new approach entails significant changes to the way PMM is understood and enacted in organizations, it has the potential to address many of the limitations of the dominant paradigm. This section outlines the implications of a SoS-based PMM paradigm and suggests a number of directions for future research that could clarify its modes of operation, outcomes and boundaries. 


\subsection{Implications for practice}

A SoS-based paradigm to PMM would have substantial implications for practice. This paradigm would question the role of PMM systems as primarily monitoring and controlling mechanisms and favour one which promotes learning and adaptation. Organizations adopting a PMM approach that does not meet the characteristics of the dominant paradigm (e.g., with practices that are loosely coupled and measures that do not appear to be fully aligned across the organization) may actually represent potential new ways to create flexibility and new knowledge using a more devolved approach that is better suited to respond to environmental turbulence. Therefore, from a SoS perspective, assessing the effectiveness of an organization's PMM system by traditional implementation criteria (e.g., close links among PMM practices and alignment between corporate and business unit measures and targets) may be misleading.

A SoS view of PMM could also have significant implications for top management teams. Senior managers have traditionally contributed to the design of corporate PMM system to create consistency and exert power throughout the organization. If their role is to become more one of orchestrators and coordinators, this may require a different set of capabilities and a greater involvement in the day-to-day operations. In other words, as a SoS is dynamic and constantly evolving, managers cannot remove themselves from operations and, by implication, from PMM itself. Their key objectives would be to improve performance continuously (rather than maximise it) and to navigate the complexity of their environments and fine-tune the composition and functioning of the PMM system. Performance management interventions may therefore need to take the shape of iterative trial-and-error approaches, pilots, and small-scale experiments rather than analytically conceived and thoroughly implemented large scale initiatives. Moreover, the balance of effort should shift from the design of PMM systems to their review (Bourne et al. 2002).

The nature of SoS would require information and reporting flows to change. A set of loosely coupled sub-systems and a diverse range of PMM approaches within a SoS are likely to bring substantial 
benefits in terms of variety and richness of information. However, this presupposes the capacity to reconcile different PMM tools and processes as well as diverse pieces of information. This will require relinquishing the focus on uniform standards and measures and instead developing and implementing processes that would allow heterogeneous insights to be examined and evaluated meaningfully in relation to each other. Interoperability, which in the dominant PMM paradigm has often been equated with the 'single version of the truth', in a SoS paradigm would require new decision-making processes that take into consideration varied and sometimes equivocal information in order to make progress and call for new tools and techniques that focus on dialogue and sensemaking.

A SoS-based view of PMM may require new ways of evaluating performance and incentivising behaviours that are congruent with top-level purpose. The emergent nature of SoS means that performance cannot be attributed to a single cause, person, or unit. This requires new models for defining and evaluating performance. For example, compensation and reward practices in SoS may need to be linked more closely with the performance of the overall system rather than the performance of constituent sub-systems. This in turn means that individual incentive schemes may need to give way to profit sharing schemes and similar mechanisms that recognise the irreducibly complex process of performance generation in SoS.

\subsection{Implications for research: A new research agenda}

Adopting a SoS perspective of PMM also has fundamental implications for research and could establish the basis for a new research agenda. Firstly, the alternative paradigm calls into question the necessity of designing and implementing effective PMM systems and managers' ability to do so. If both the organization and the environment are complex and rapidly changing, what does 'design' or 'implement' a PMM system mean? How will managers be able to design PMM tools when sub-systems are autonomous and their configuration is constantly evolving? Who may need to be involved in the process? 
Secondly, further research will need to identify and explain the characteristics of the independent systems that are likely to form a SoS. Most importantly, new research will be required to extend our knowledge of how these systems are interrelated to enable the measurement and management of performance (especially in cross-functional processes and inter-organizational contexts such as supply chains), and how the different systems are configured to ensure the alignment between strategic and operational levels ${ }^{1}$. Recent work on the technical and social controls of PMM (Smith and Bititci 2017) or previous research on the components of management control systems (Bedford, Malmi, and Sandelin 2016; Malmi and Brown 2008; Ferreira and Otley 2009) could form the foundations for these investigations.

Thirdly, given the crucial role of autonomy of the constituent sub-systems within a SoS, scholars will need to investigate what affects the capacity and functionality of these systems. Autonomy assumes that the constituent sub-systems learn and adapt, which means that they cannot be viewed simply as providing additional capacity or specific functional support. Rather, they can evolve in a way that may either support or damage the overall SoS. Therefore, it may be useful to examine the role of sub-systems through analytical lenses provided by the work on capabilities (Foss et al. 2012), which would allow scholars to examine the origin, functionality, and evolution of individual sub-systems, or absorptive capacity (Zahra and George 2002), which may enable researchers to understand and estimate a sub-system's potential to learn.

Fourthly, while SoS are described by five main characteristics, it would be useful to investigate empirically whether all attributes should be present at the same time or whether they could vary depending on context. For example, in a unitary organization, heterogeneity of constituent parts may be appropriate, yet choice regarding whether to belong to the organization may not be possible. What might be the implications of selective application of SoS characteristics? Variations in these characteristics are

\footnotetext{
${ }^{1}$ We thank an anonymous reviewer for these insightful observations.
} 
likely to be associated with different forms of SoS as some researchers are already proposing (Sauser, Boardman, and Verma 2010; Vaneman and Jaskot 2013).

Fifthly, empirical research could be expressly conducted in organizations that operate in highly turbulent contexts and that have developed PMM systems that do not align with the current dominant paradigm. Which features have they intentionally changed (e.g., strategic objectives and measures may have become loosely coupled)? Which PMM practices have been discarded (e.g., annual performance appraisals) (Cappelli and Tavis 2016)? And how do their PMM systems compare with the one that would be postulated by the SoS paradigm?

Finally, a SoS-based view of PMM may require alternative or revised research methods. The use of simulation and modelling, for example, may need do become more prominent, as the goal of the researchers would be to understand what nudges the entire system in one direction or another and how the system as a whole may respond to different initial conditions, rather than trying to discover specific causes of organizational performance.

\section{References}

Ackoff, R. 1971. 'Towards a System of Systems Concepts'. Management Science 17 (11): 661-71.

Akyuz, G.A., T.E. Erkan, G. Arzu Akyuz, and T. Erman Erkan. 2010. 'Supply Chain Performance Measurement: A Literature Review'. International Journal of Production Research 48 (17): 5137-55.

Baldwin, C.W., J.T. Boardman, and B.J. Sauser. 2013. 'Expanding a System of Systems Model with the Schelling Segregation Model'. Systems Research and Behavioral Science 30: 65-75.

Bedford, D.S., T. Malmi, and M. Sandelin. 2016. 'Management Control Effectiveness and Strategy: An Empirical Analysis of Packages and Systems'. Accounting, Organizations \& Society 51: 12-28.

Berrah, L., G. Mauris, and F. Vernadat. 2004. 'Information Aggregation in Industrial Performance Measurement Rationales, Issues and Definitions'. International Journal of Production Research 42 (20): 4271-93.

Bititci, U., P. Garengo, V. Dörfler, and S. Nudurupati. 2012. 'Performance Measurement: Challenges for Tomorrow'. International Journal of Management Reviews 14 (3): 305-27. 
Bititci, U.S, P. Garengo, A. Ates, and S.S Nudurupati. 2015. 'Value of Maturity Models in Performance Measurement'. International Journal of Production Research 53 (10): 3062.

Boardman, J., and B. Sauser. 2006. 'System of Systems - the Meaning of of'. In IEEE/SMC International Conference on System of Systems Engineering, 1-6.

Bourne, M, and P. Bourne. 2011. Handbook of Corporate Performance Management. Chichester, UK: Wiley.

Bourne, M., J. Mills, M Wilcox, A. Neely, and K. Platts. 2000. 'Designing, Implementing and Updating Performance Measurement Systems'. International Journal of Operations and Production Management 20 (7): 754-71.

Bourne, M., A. Neely, K. Platts, and J. Mills. 2002. 'The Success and Failure of Performance Measurement Initiatives: Perceptions of Participating Managers'. International Journal of Operations and Production Management 22 (11): 1288-1310.

Bunge, M. 2014. Emergence and Convergence: Qualitative Novelty and the Unity of Knowledge. Toronto: University of Toronto Press.

Buytendijk, F., T. Hatch, and P. Micheli. 2010. 'Scenario-Based Strategy Maps'. Business Horizons 4: 335-47.

Cappelli, P., and A. Tavis. 2016. 'The Performance Management Revolution'. Harvard Business Review, no. October.

Chan, H.K. 2011. 'Supply Chain Systems - Recent Trend in Research and Applications'. IEEE Systems Journal $5(1): 2-5$.

Chanand, H.K., and F.T.S. Chan. 2009. 'Effect of Informationsharing in Supply Chains with Flexibility'. International Journal of Production Research 47 (1): 213-32.

Chandler, A. 1977. The Visible Hand. Cambridge, Mass: The Belknap Press of Harvard University Press.

Cross, K.F., and R.L. Lynch. 1989. 'The SMART Way to Define and Sustain Success'. National Productivity Review 9 (1): 23-33.

Dahler-Larsen, P. 2014. 'Constitutive Effects of Performance Indicators: Getting beyond Unintended Consequences'. Public Management Review 16 (7): 969-86.

Danese, P., and P. Romano. 2012. 'Relationship between Downstream Integration, Performance Measurement Systems and Supply Network Efficiency'. International Journal of Production Research 50 (7): 2002.

DeLaurentis, D.A., and S. Ayyalasomayajula. 2009. 'Exploring the Synergy between Industrial Ecology and System of Systems to Understand Complexity a Case Study in Air Transportation'. Journal of Industrial Ecology 13 (2): 247-63.

DeLaurentis, D.A., and R. Callaway. 2004. 'A System-of-Systems Perspective for Public Policy Decisions'. Review of Policy Research 21 (6): 829-38.

Dossi, A., and L. Patelli. 2010. 'You Learn from What You Measure: Financial and Non-Financial Performance Measures in Multinational Companies'. Long Range Planning 43 (4): 498-526. 
Dror, S., and M. Barad. 2011. 'House of Strategy (HOS): From Strategic Objectives to Competitive Priorities'. International Journal of Production Research 44 (18-19): 3879-95.

Ferreira, A., and D.T. Otley. 2009. 'The Design and Use of Performance Management Systems: An Extended Framework for Analysis'. Management Accounting Research 20 (4): 263-82.

Fitzgerald, L., R. Johnston, S. Brignall, R. Silvestro, and C. Voss. 1991. 'Performance Measurement in Service Businesses'. London, UK.

Foss, N. J., K.H. Heimeriks, S. Winter, and M. Zollo. 2012. 'A Hegelian Dialogue on the Micro-Foundations of Organizational Routines and Capabilities'. European Management Review 9: 173-197.

Franco-Santos, M., M. Kennerley, P. Micheli, V. Martinez, S. Mason, B. Marr, Dina Gray, and Andrew Neely. 2007. 'Towards a Definition of a Business Performance Measurement System'. International Journal of Operations \& Production Management 27 (8): 784-801.

Franco-Santos, M., L. Lucianetti, and M. Bourne. 2012. 'Contemporary Performance Measurement Systems: A Review of Their Consequences and a Framework for Research'. Management Accounting Research 23 (2): 79-119.

Gimbert, X., J. Bisbe, and X. Mendoza. 2010. 'The role of performance measurement systems in strategy formulation processes', Long Range Planning 43(4): 477-497.

Glassman, R.B. 1973. 'Persistence and Loose Coupling in Living Systems'. Systems Research and Behavioral Science 18: 83-98.

Gorod, A., S.J. Gandhi, B. Sauser, and J. Boardman. 2008. 'Flexibility of System of Systems'. Global Journal of Flexible Systems Management 9 (4): 21-31.

Hanson, J.D., S. Melnyk, and R. Calantone. 2011. 'Defining and Measuring Alignment in Performance Management'. International Journal of Operations and Production Management 31 (10): 1089-1114.

Hoque, Z. 2014. '20 Years of Studies on the Balanced Scorecard: Trends, Accomplishments, Gaps and Opportunities for Future Research'. British Accounting Review 46 (1): 33-59.

Ittner, C.D., and D.F. Larcker. 2003. 'Coming up Short on Nonfinancial Performance Measurement'. Harvard Business Review 81 (11): 88-95.

Ittner, C.D., D.F. Larcker, and T. Randall. 2003. 'Performance Implications of Strategic Performance Measurement in Financial Services Firms'. Accounting, Organizations and Society 28 (7-8): 715-41.

Johnson, H.T. 1981. 'Toward a New Understanding of Nineteenth-Century Cost Accounting'. The Accounting Review 56 (3): 510-18.

Johnson, H.T., and R.S. Kaplan. 1987. Relevance Lost - The Rise and Fall of Management Accounting. Boston, MA: Harvard Business School Press.

Kaplan, R.S., and D.P. Norton. 2000. 'Having Trouble with Your Strategy? Then Map It.' Harvard Business Review 78 (5): 167-76, 202.

- - 2008. The Execution Premium. Boston, MA: Harvard Business School Press. 
Kaplan, R.S., and P.D. Norton. 1996. 'Linking the Balanced Scorecard to Strategy'. California Management Review 39 (1): 53-79.

Keating, C., J. Padilla, and K. Adams. 2008. 'System of Systems Engineering Requirements: Challenges and Guidelines'. Engineering Management Journal 20 (4): 24-31.

Keating, C., R. Rogers, R. Unal, D. Dryer, A. Sousa-poza, R. Safford, W. Peterson, and G. Rabadi. n.d. 'System of Systems Engineering'.

Keegan, D.P., R.G. Eiler, and C.R. Jones. 1989. 'Are Your Performance Measures Obsolete?' Management Accounting 70 (12): 45-50.

Kerr, S. 1995. 'On the Folly of Rewarding A, While Hoping for B'. Academy of Management Executive 9 (1): 7-14.

Kolehmainen, K. 2010. 'Dynamic Strategic Performance Measurement Systems: Balancing Empowerment and Alignment'. Long Range Planning 43 (4): 527-54.

Koufteros, X., A. Verghese, and L. Lucianetti. 2014. 'The Effect of Performance Measurement Systems on Firm Performance: A Cross-Sectional and a Longitudinal Study'. Journal of Operations Management 32 (6): 313-36.

Liang, Y.H. 2015. 'Performance Measurement of Interorganizational Information Systems in the Supply Chain'. International Journal of Production Research 53(18): 5484-5499.

Lo, C.K.Y., M. Pagell, D. Fan, F. Wiengarten, and A.C.L. Yeung. 2014. 'OHSAS 18001 Certification and Operating Performance: The Role of Complexity and Coupling' . Journal of Operations Management 32 (5): 268-80.

Maestrini, V., D. Luzzini, P. Maccarrone, and F. Caniato. 2017. 'Supply Chain Performance Measurement Systems: A Systematic Review and Research Agenda'. International Journal of Production Economics 183: $299-315$

Mahmood, A. 2016. "SoS Call" at the Other Edge of Chaos'. Journal of Systems Science and Complexity 29 (1): 133-50.

Maier, Mark W. 1998. 'Architecting Principles for Systems-of-Systems'. Systems Engineering 1 (4): 267-84.

Malmi, T., and D.A. Brown. 2008. 'Management Control Systems as a Package-Opportunities, Challenges and Research Directions'. Management Accounting Research 19 (4): 287-300.

Martinez, V., A. Pavlov, and M. Bourne. 2010. 'Reviewing Performance: An Analysis of the Structure and Functions of Performance Management Reviews'. Production Planning \& Control 21 (1): 70-83.

McGrath, R. 2013. 'Transient Advantage'. Harvard Business Review 91 (6): 62-70.

Melnyk, S.A., U. Bititci, K. Platts, J. Tobias, and B. Andersen. 2014. 'Is Performance Measurement and Management Fit for the Future?' Management Accounting Research 25 (2). Elsevier Ltd: 173-86.

Melnyk, S.A., D.M. Stewart, and M. Swink. 2004. 'Metrics and Performance Measurement in Operations Management: Dealing with the Metrics Maze'. Journal of Operations Management 22 (3): 209-18. 
Micheli, P., and L. Mari. 2014. 'The Theory and Practice of Performance Measurement'. Management Accounting Research 25 (2). Elsevier Ltd: 147-56.

Micheli, P., and M. Mura. 2017. 'Executing Strategy through Comprehensive Performance Measurement Systems'. International Journal of Operations and Production Management.

Micheli, P., and A. Neely. 2010. 'Performance Measurement in the Public Sector in England: Searching for the Golden Thread'. Public Administration Review 70 (4): 591-600.

Mostafavi, A., D.M. Abraham, D.A. DeLaurentis, and J. Sinfield. 2011. 'Exploring the Dimensions of Systems of Innovation Analysis: A System of Systems Framework'. IEEE Systems Journal 5 (2): 256-65.

Neely, A. 2005. 'The Evolution of Performance Measurement Research: Developments in the Last Decade and Research Agenda for the next'. International Journal of Operations \& Production Management 25 (12): 1264-77.

Neely, A., C. Adams, and M. Kennerly. 2002. The Performance Prism: The Scorecard for Measuring and Managing Business Success. London, UK: FT Prentice Hall.

Neely, A., and M. Al Najjar. 2006. 'Management Learning Not Management Control: The True Role of Performance Management?' California Management Review 48 (3): 101-14.

Neely, A., P. Micheli, and V. Martinez. 2006. Acting on Information: Performance Management for the Public Sector. London, UK: Advanced Institute of Management Research

Otley, D.T., and A.J. Berry. 1980. 'Control, Organisation and Accounting'. Accounting, Organizations and Society 5 (2): 231-44.

Otley, D.T., and K. Soin. 2015. Management Control and Uncertainty. Basingstoke: Palgrave Macmillan.

Pongatichat, P., and R. Johnston. 2008. 'Exploring Strategy-misaligned Performance Measurement'. International Journal of Productivity and Performance Management 57 (3): 207-22.

Rechtin, E. 1991. System Architecting: Creating and Building Complex Systems. Englewood Cliffs, NJ.: Prentice-Hall.

Ridgway, V.F. 1956. 'Dysfunctional Consequences of Performance Measurements'. Administrative Science Quarterly 1 (2): 240-47.

Rittel, H.W.J., and M.M. Webber. 1973. 'Dilemmas in a General Theory of Planning'. Policy Sciences 4 (2): 155-69.

Sauser, B., and J. Boardman. 2008. 'System of Systems Management'. Engineering Management Journal 20 (4): 191-217.

Sauser, B., J. Boardman, and D. Verma. 2010. 'Systomics: Toward a Biology of System of Systems'. IEEE Transactions on Systems, Man, and Cybernetics Part A:Systems and Humans 40 (4): 803-14.

Smith, M., and U. Bititci. 2017. 'Interplay between Performance Measurement and Management, Employee Engagement and Performance'. International Journal of Operations and Production Management. 
Srimai, S., C. Wright, and J. Radford. 2013. 'A Speculation of the Presence of Overlap and Niches in Organizational Performance Management Systems'. International Journal of Productivity and Performance Management 62 (4): 364-86.

Svendsen, A.D.M. 2015. 'Advancing "Defence-in-Depth": Intelligence and Systems Dynamics'. Defense \& Security Analysis 31 (1): 58-73.

Tsan-Ming, C. 2016. Service Supply Chain Systems: A Systems Engineering Approach. London, UK.: Taylor \& Francis Ltd.

Vaneman, W.K., and R.D. Jaskot. 2013. 'A Criteria-Based Framework for Establishing System of Systems Governance'. SysCon 2013 - 7th Annual IEEE International Systems Conference, Proceedings, 491-96.

Weick, Karl E. 1976. 'Educational Organizations as Loosely Coupled Systems'. Administrative Science Quarterly 21 (1): 1-19. doi:10.2307/2391875.

Yang, C., and S. Modell. 2015. 'Shareholder Orientation and the Framing of Management Control Practices: A Field Study in a Chinese State-Owned Enterprise'. Accounting, Organizations and Society 45: 11-23.

Zahra, S.A., and G. George. 2002. 'Absorptive Capacity: A Review, Reconceptualization, and Extensio'. Academy of Management Review 27 (2): 185-203.

Zhu, J., and A. Mostafavi. 2014. 'A System-of-Systems Framework for Performance Assessment in Complex Construction Projects'. Organization, Technology \& Management in Construction: An International Journal 6 (3): 1083-93. 